\title{
Thermal constants of egg development in carabid beetles - variation resulting from using different estimation methods and among geographically distant European populations
}

\author{
Pavel SASKA ${ }^{1}$, Miroslav VLACH ${ }^{1,2}$, Jana SCHMIDTOVÁ² and Andrey V. MATALIN ${ }^{3,4}$ \\ ${ }^{1}$ Crop Research Institute, Drnovská 507, Praha 6 - Ruzyně, 161 06, Czech Republic; e-mail: saska@vurv.cz \\ ${ }^{2}$ Czech University of Life Sciences, Kamýcká 129, Praha 6 - Suchdol, 165 21, Czech Republic; \\ e-mails: vlach.miroslav@centrum.cz; rogerfoxie@gmail.com \\ ${ }^{3}$ Moscow State Pedagogical University, Zoological \& Ecological Department, Kibalchitcha 6, bldg. 5, Moscow 129164, \\ Russian Federation; e-mail: a matalin@tochka.ru \\ ${ }^{4}$ Russian National Research Medical University named after N.I. Pirogov, Department of Biology, Ostrovitianova 1, \\ Moscow 117997, Russian Federation
}

Key words. Coleoptera, Carabidae, temperature, thermal constants, law of total effective temperatures, lower development threshold, sum of effective temperatures, duration of development, development rate, mortality

\begin{abstract}
Using equations based on the law of total effective temperatures, we estimated the thermal constants ( $L D T$, the lower development threshold, and SET, the sum of effective temperatures) of egg development for 14 populations of 13 species of carabid beetles (eight belonging to the tribe Zabrini, one to Platynini and four to Pterostichini). We compared the estimates of the thermal constants obtained using three commonly used equations $(D=S E T /(T-L D T) ; 1 / D=a+b \cdot T$, where $L D T=-a / b$, and $S E T=1 / b$; and $D \cdot T=$ $S E T+D \cdot L D T)$ and two data formats: data points for all the individuals and means for each temperature. We found that, for most species, estimates of both $L D T$ and SET of egg development obtained using the three models were similar and that using means resulted in larger standard errors (SE) than using all data points. We provide evidence for inter-correlation among the thermal constants, showing that a decrease in the estimate of one constant is accompanied by an increase in the estimate of the other constant. For seven species for which sufficient data were available we investigated the geographical variation in their thermal constants. We found significant variation in both constants for three species, in only one in one species and in three species there was no significant variation among geographically distant populations at $\mathrm{p}<0.05$. For eight out of the nine autumn-breeding species studied, egg mortality significantly increased at high temperatures. For future studies, we recommend the use of the third method $(D \cdot T=S E T+D \cdot L D T)$ for estimating thermal constants for several reasons: (i) it is linear (i.e., simple to compute); (ii) the thermal constants are parameters of the equation, and therefore, their SEs are directly estimated; (iii) it allows the use of all data points (i.e., reduces the SE of the estimates of thermal constants); and (iv) the thermal requirements of different species or populations can be directly compared using ANCOVA.
\end{abstract}

\section{INTRODUCTION}

Within the range of ecologically relevant temperatures, the relationship between temperature $(T)$ and the duration of development $(D)$ of a species or population can be described by a formula generally known as the law of total effective temperatures (recently reviewed by Damos \& Savopoulou-Soultani, 2012):

$k=D \cdot(T-t)$

The strength of eq. (1) lies in its simplicity; it introduces two thermal constants for the development of the individuals of a particular population. The first constant describes the temperature when the development of an individual of a particular population ceases, denoted as $t$ in eq. (1), which may be called the lower development threshold $(L D T)$, thermal threshold for development (TTD), minimum temperature $\left(T_{\min }, t_{\min }\right)$, developmental zero $\left(T_{0}\right)$ or base temperature $\left(T_{b}\right)$, respectively (Honěk, 1996b; Stacey \& Fellowes, 2002; Kontodimas et al., 2004; Trudgill et al., 2005; Koda \& Nakamura, 2012; Lopatina et al., 2012b). The second constant represents the amount of heat above the temperature threshold that needs to be accumulated to complete the development of a particular stage in their development, denoted as $k$ in eq. (1), which may also be called the sum of effective temperatures (SET), day degrees required $(D D R)$, sum of day-degrees $(S D D)$ or thermal constant $(K)$, respectively (Honěk, 1996b; Stacey \& Fellowes, 2002; Kontodimas et al., 2004; Trudgill et al., 2005).

Thermal constants are important descriptors of the thermal requirements of a species or a population and their adaptations to local climatic conditions (Bonato et al., 2011; Jarošík et al., 2011). From that perspective, the models describing temperature-development relationships based on temperature summations are more useful in practice than most of the non-linear models (for examples and review, see Kontodimas et al., 2004; Damos \& Savopoulou-Soultani, 2012). Thermal constants can be used in models to predict the onset of development and timing of activity of a species, e.g., in biological control when knowing the time of emergence is crucial for deciding when to apply management practices.

The concept of thermal constants appears to apply to most ectothermic organisms (Jarošík et al., 2004). For this 
reason, it is important to understand what determines the variation in the estimates of the thermal constants. There is increasing evidence that related species or populations of species that share the same environment in a climatic zone have similar thermal constants, mainly similar $L D T s$ (Jarošík et al., 2011). Among species, there are geographical trends in thermal constants and in nematodes and insects $L D T$ generally decreases and SET increases with latitude (Trudgill \& Perry, 1994; Honěk, 1996a). However, there are fewer studies on how thermal constants vary between populations of the same species living in different environments or climatic zones, and the support for similar intra-specific variation is rather weak (Stacey \& Fellowes, 2002; Lopatina et al., 2012a, b).

This study has four major aims. The first is to report the thermal constants of egg development in 13 species of carabid beetles, including seven species for which the thermal constants have not been previously reported. The second is to compare estimates of the thermal constants for development obtained in six different ways, using three models each applied to two data formats. Third, determine the differences in the estimates of the thermal constant of egg development recorded for geographically distant populations of seven species using newly collected data and data extracted from the literature. Finally, we determine the effect of temperature on egg survival in the species studied.

\section{MATERIAL AND METHODS}

\section{Rearing}

In total, we obtained sufficient data for 14 populations of 13 species of carabid beetles. The eggs were obtained from adult pairs, which were collected in the field either by hand or using pitfall traps. The adults of the species studied originated as follows (species reproducing in autumn and winter are marked by an asterisk):

Zabrini: *Amara aulica (Panzer): Bohemia centr., PrahaRuzyně 25.8.2002, 20.8.2003, Pavel Saska lgt.; *A. bifrons (Gyllenhal): Bohemia centr., Praha-Ruzyně, 20.9.2011, 20.8.2012, Pavel Saska lgt.; A. convexior Stephens: Bohemia centr., PrahaRuzyně, 17.5.2013, Pavel Saska lgt.; *A. convexiuscula (Marsham): Bohemia centr., Praha-Ruzyně 21.8.2001, 25.8.2002, Pavel Saska lgt.; *A. equestris (Duftschmid): Russian Federation, Moscow Area, Nikiforovo, 5.9.2012, Pavel Saska and Andrey Matalin lgt.; *A. eurynota (Panzer): Bohemia centr., Praha-Ruzyně, 1.10.2012, Pavel Saska lgt.; Russian Federation, Moscow Area, Troitse-Seltso, 9.9.2012, Pavel Saska and Andrey Matalin lgt.; *A. municipalis (Duftschmid): Bohemia centr., Praha-Ruzyně, 1.10.2012, Pavel Saska lgt.; *A. sabulosa (Audinet-Serville): Bohemia centr., Praha-Ruzyně 20.8.2003, 20.9.2011, Pavel Saska lgt.; Platynini: Platynus assimilis (Paykull): Bohemia centr., Praha-Divoká Šárka, 12.5.2013, Pavel Saska and Miroslav Vlach lgt.; Pterostichini: Poecilus cupreus (Linnaeus): Bohemia centr., Praha-Ruzyně, 20.5.2012, Pavel Saska lgt.; P. versicolor (Sturm): Bohemia centr., Sedlčany env., 13.6.2013, Michal Knapp lgt.; *Pterostichus melanarius (Illiger): Bohemia centr., Praha-Krč, Zátišský potok, 3.8.2012, Jana Schmidtová lgt.; Bohemia centr., Praha-Ruzyně, 10.8.2012, Pavel Saska lgt.; P. oblongopunctatus (Fabricius): Bohemia centr., Praha-Divoká Šárka, 12.5.2013, Pavel Saska and Miroslav Vlach lgt.

Depending on their size adults were kept either in pairs or in small groups in glass Petri dishes, which ranged in size from 9 to $15 \mathrm{~cm}$ in diameter and 1 to $3 \mathrm{~cm}$ deep, filled to a depth equal to one-half of the depth of the dish with sieved garden soil. The adults were fed with pieces of Tenebrio molitor larvae and granivorous species of the genera Amara, with seeds of the species' preferred plant, if known, or with seeds of the most abundant plant at the site where the species was collected (Taraxacum officinale, Artemisia vulgare, Urtica dioica, Tripleurospermum inodorum, Viola arvense) (Honěk et al., 2007; P. Saska, unpubl.). The dishes were checked daily for eggs; the soil was spread in a photographic tray and eggs recovered were reared at different temperatures. Because some species tended to attach their eggs to the walls and bottom of the dishes, these areas were also carefully inspected.

The eggs were transferred to small glass Petri dishes $(5 \mathrm{~cm}$ in diameter, $1 \mathrm{~cm}$ deep) filled to a depth of $0.5 \mathrm{~cm}$ with a mixture of plaster of Paris and charcoal saturated with tap water (Saska \& Honěk, 2003). The eggs were placed on the surface of the plaster. The dishes with eggs were randomly distributed among climatic chambers, which maintained the experimental temperatures $\pm 0.5^{\circ} \mathrm{C}$ and a long day (18L : 6D) photoperiod. The set temperatures ranged from 9 to $29^{\circ} \mathrm{C}$, and each species was reared at 4 to 7 different temperatures, depending on the species. The actual temperatures within the chambers were monitored using TinyTag ${ }^{\circledR}$ dataloggers (Gemini Dataloggers, Chichester, UK). The average temperature recorded over the experimental period for each carabid species was used in the calculations.

\section{Methods of estimating the thermal constants}

In this study, we used three models to estimate the thermal constants, all derived from the law of total effective temperatures (eq. 1). In all of the formulas presented below, $D$ is the duration of development, $T$ the temperature, $L D T$ the lower development threshold and $S E T$ the sum of effective temperatures.

$D=S E T /(T-L D T)$

(e.g., Ikemoto, 2003; Kontodimas et al., 2004),

$1 / D=a+b \cdot T$

where $L D T=-a / b$, and $S E T=1 / b$ (e.g., Campbell et al., 1974; Honěk, 1996a, b)

$D \cdot T=S E T+D \cdot L D T$

(Ikemoto \& Takai, 2000).

All three models were employed using two formats of the data on the duration of development: (i) data points for all individuals and (ii) arithmetic means for each temperature. Both approaches have been used in previous studies, for eq. (2) and (3) (e.g., Campbell et al., 1974; Honěk, 1996a, b; vs. Lopatina et al., 2012a, b), although using means is more statistically appropriate as it satisfies the assumptions of regression analysis (equal sample size and variance among temperatures, removing pseudo-replications; see Ikemoto \& Takai (2000) for discussion). Eq. (4) was developed to enable the use of all data points in the analysis, and therefore, to increase precision (Ikemoto \& Takai, 2000); thus, conducting this analysis on means may appear redundant. However, we show below that this approach may be useful in some situations. All approaches are visualised in Fig. 1.

The analysis was performed in R version 15.2.0 (R Development Core Team, 2013), using ordinary linear regression in the cases of eqs (3) and (4) and non-linear regression in the case of eq. (2). Although the reduced major axes regression (RMA) is recommended for eq. (4) (Ikemoto \& Takai, 2000), we preferred using ordinary regression in this paper as both types of regression provided nearly identical estimates of thermal constants in our case (data not shown) and ordinary regression is easier to compute. Prior to analyses we excluded data for temperatures that showed deviations from linearity. The precision of the estimates 

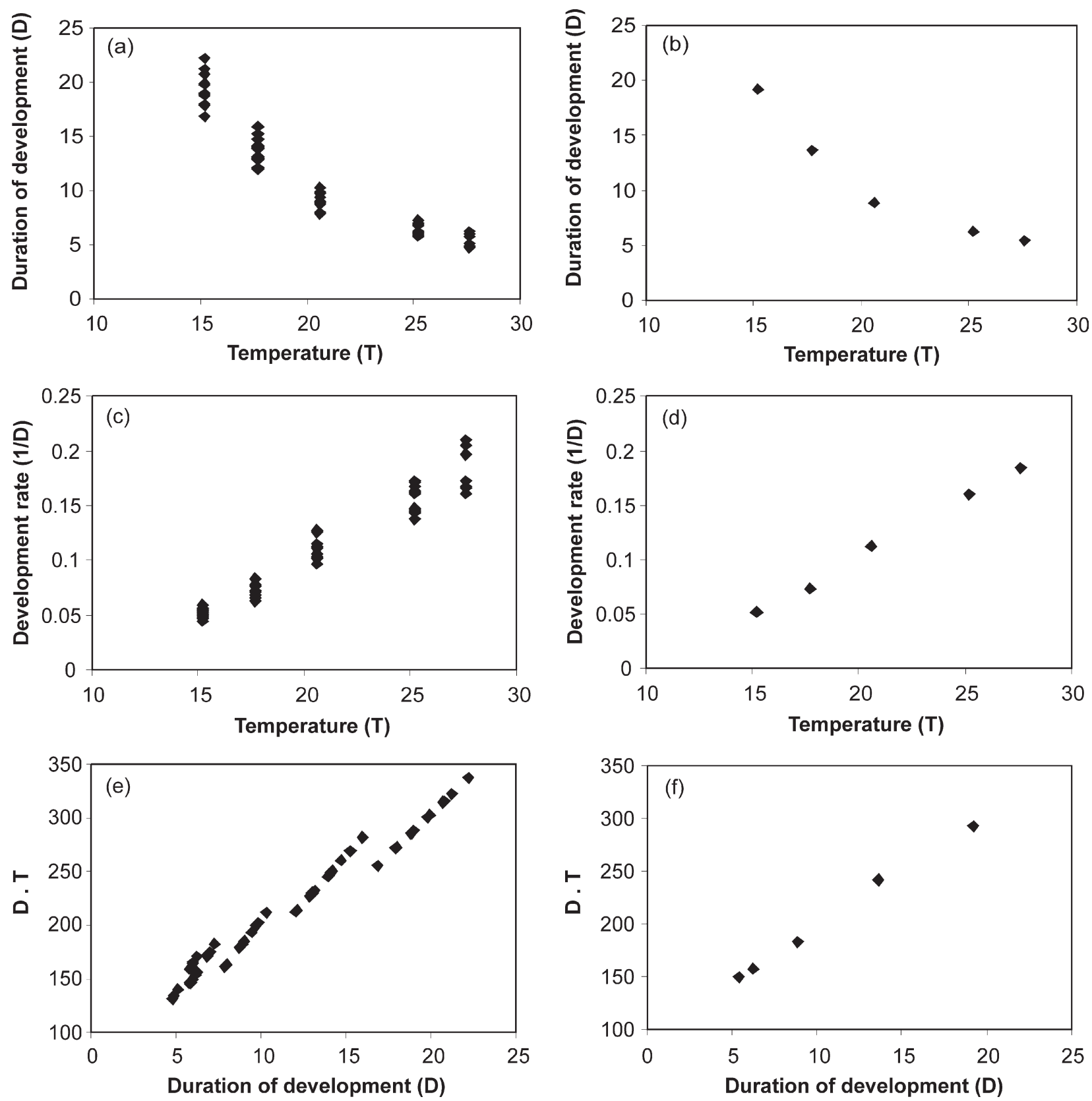

Fig. 1. Graphical illustration of the results of using six ways of estimating thermal constants, based on data for Poecilus versicolor. (a-b) eq. 2: $D=S E T /(T-L D T)$; (c-d) eq. $3: 1 / D=a+b \cdot T$, where $S E T=1 / b$ and $L D T=-a / b$; (e-f) eq. $4: D \cdot T=S E T+L D T \cdot D$. (a), (c) and (e) use all the data points, whereas (b), (d) and (f) use the means for each temperature.

of $L D T$ and SET were expressed in terms of the SE of the estimates. SE's were computed automatically from the model by the statistical software during the parameter estimation in the case of eqs (2) and (4), and in the case of eq. (3), we used the formulas provided by Campbell et al. (1974). The existence of an inter-correlation between the estimates of $L D T$ and SET originated from the different approaches and was tested using a correlation test for each species separately.

\section{Geographical variation in thermal constants}

The geographical variation in the estimates of thermal constants among populations of the same species was determined using data presented in this paper together with data available in the literature. The data from the literature used in this study are listed in Table 1. The thermal constants of A. convexior from the Czech Republic were compared with those of $A$. communis from the Russian Federation because these species are closely related (one species aggregate; Hůrka \& Jarošík, 2001). Eq. (4) using the mean durations of development recorded at each temperature was used to compare the thermal constants of geographically distant populations. Means had to be used as only these were available in the literature. Eq. (4) was chosen because (i) it provides estimates of the thermal constants directly as parameters of the regression together with their SE, (ii) it is linear, and therefore easy to compute, and (iii) it allows for testing the possible differences in thermal constants among populations using analysis of covariance, where population is the factor. The significant differences in thermal constants among populations were determined using a ttest (Sokal \& Rohlf, 1981). The variation in the thermal constants was visualised by plotting them against the geographical latitude of the site of origin of the parental populations. 
TABle 1. Data on the thermal constants obtained from the literature used in this study. $\mathrm{N}$ - geographical latitude, $\mathrm{E}$ - geographical longitude.

\begin{tabular}{|c|c|c|c|c|c|c|c|c|c|}
\hline Locality & $\mathrm{N}$ & E & 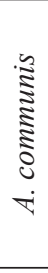 & 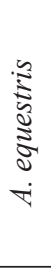 & 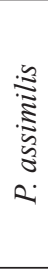 & $\begin{array}{l}\vdots \\
\vdots \\
0 \\
0 \\
0 \\
\vdots \\
0 \\
0\end{array}$ & 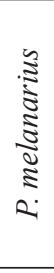 & 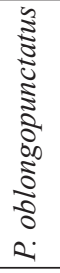 & Reference \\
\hline Praha & $50^{\circ} 05^{\prime}$ & $14^{\circ} 20^{\prime}$ & & $*$ & & & & & Saska \& Honěk, 2003 \\
\hline Burscheid & $51^{\circ} 05^{\prime}$ & $7^{\circ} 07^{\prime}$ & & & & & & $*$ & Paarmann, 1966 \\
\hline Baarn & $52^{\circ} 12^{\prime}$ & $5^{\circ} 15^{\prime}$ & & & & & & $*$ & Heesen et al., 1982 \\
\hline Bryansk & $53^{\circ} 14^{\prime}$ & $34^{\circ} 22^{\prime}$ & & & & $*$ & & & Lopatina et al., 2012a, b \\
\hline Moscow & $55^{\circ} 45^{\prime}$ & $37^{\circ} 37^{\prime}$ & & & $*$ & & & * & Lopatina et al., 2012b \\
\hline St. Petersburg & $59^{\circ} 56^{\prime}$ & $30^{\circ} 18^{\prime}$ & $*$ & & $*$ & $*$ & $*$ & $*$ & Lopatina et al., 2012b \\
\hline Archangelsk & $64^{\circ} 32^{\prime}$ & $40^{\circ} 32^{\prime}$ & $*$ & & $*$ & $*$ & $*$ & $*$ & Lopatina et al., 2012b \\
\hline
\end{tabular}

\section{Effect of temperature on egg mortality}

The effect of temperature on egg mortality was assessed using the saturated GLM logistic analogue of the analysis of variance with binomial structure of errors (GLM-b) (Crawley, 2007). Tem-
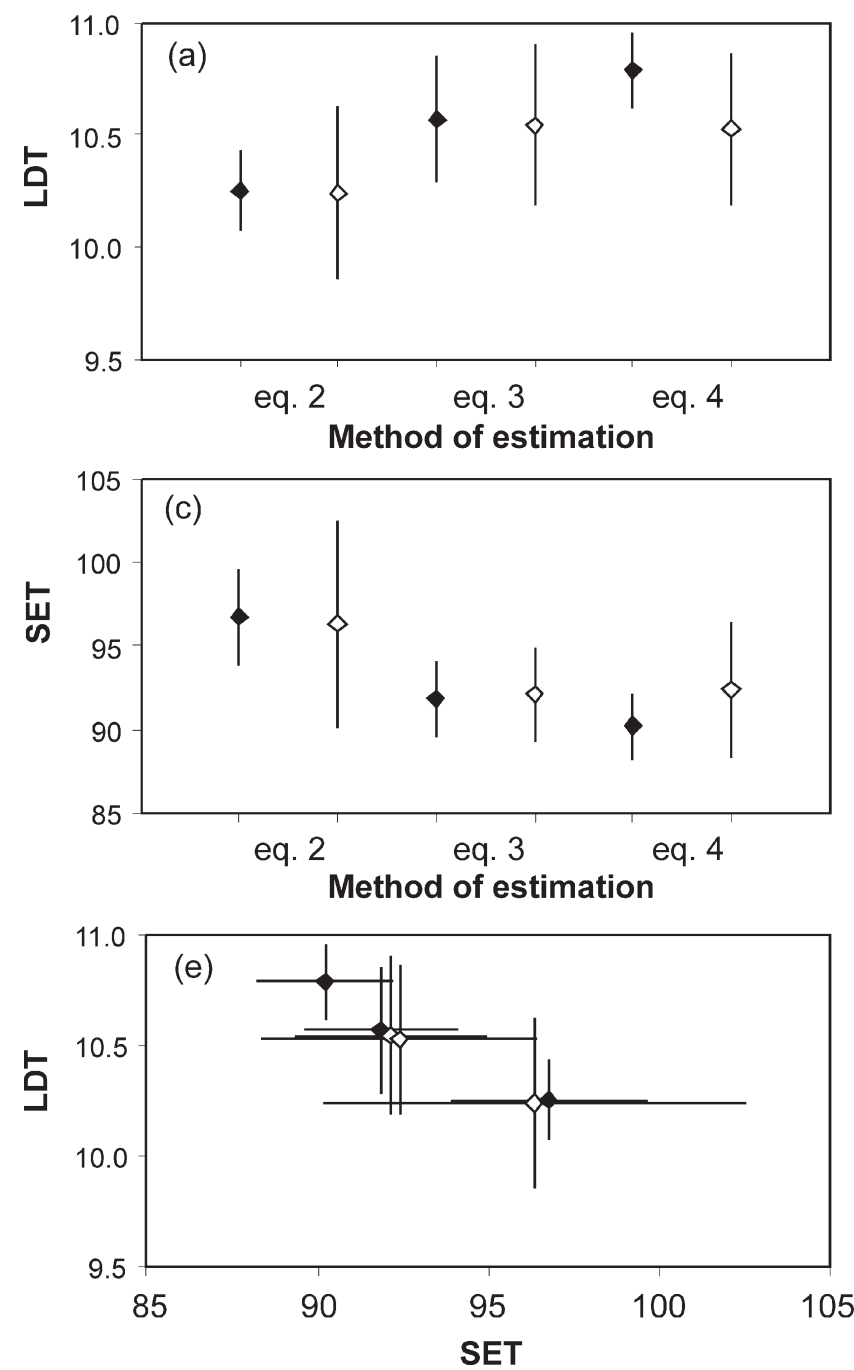

perature was used as the only explanatory variable (factor), and the binomial vector that contained the information on the number of hatched and dead individuals per temperature was used as the response variable. The analysis was performed for each species separately.
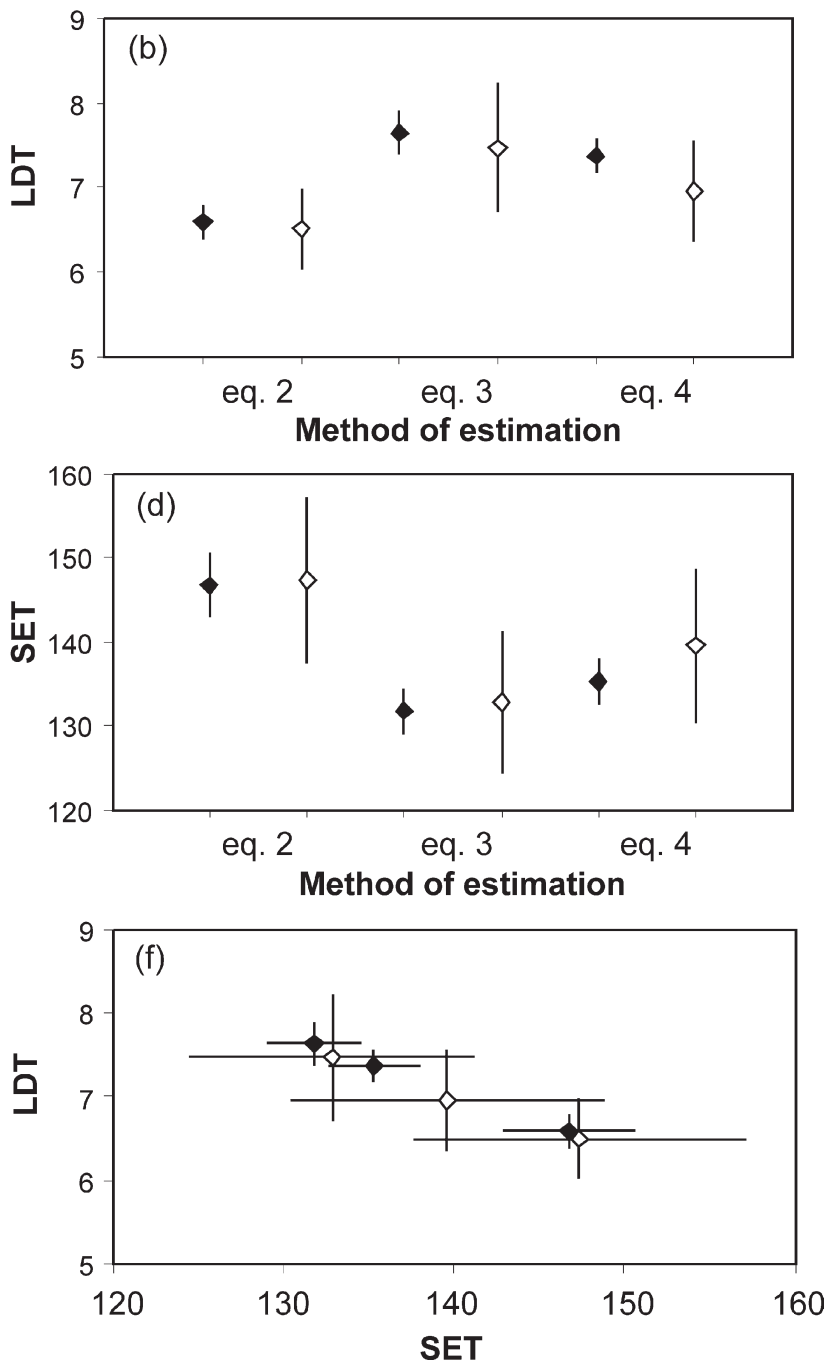

Fig. 2. Examples of within-species variation and inter-correlations between the estimated values of the thermal constants of egg development obtained using the different approaches. Error bars represent SE: (a-b) variation in LDT; (c-d) variation in SET; (e-f) inter-correlation between LDT and SET. (a), (c) and (e) - Poecilus versicolor; (b), (d) and (f) - Pterostichus melanarius. Filled symbols - all data points used, empty symbols - means used. 
TABLE 2. Mean duration of development and survival of eggs of carabid beetles from 14 populations kept at different temperatures. $\mathrm{a}$ - autumn breeding species; $\mathrm{s}$ - spring breeding species; $\mathrm{w}$ - winter breeding species; CZ - Czech Republic; RUS - Russian Federation; $\mathrm{N}$ - number of eggs used for calculating mean duration of development $\pm \mathrm{SE}$. Significance of differences in survival was assessed based on a $\chi^{2}$-test (saturated GLM-b).

\begin{tabular}{|c|c|c|c|c|c|c|c|c|}
\hline Species & Breeding type & Population & Temperature & $\mathrm{N}$ & Mean duration of development & \% Survival & Deviance & $\mathrm{P}$ \\
\hline A. aulica & $\mathrm{a}$ & $\mathrm{CZ}$ & $\begin{array}{l}11.9 \\
15.6 \\
18.6 \\
22 \\
25.1 \\
27.9\end{array}$ & $\begin{array}{l}4 \\
3 \\
7 \\
6 \\
5 \\
\end{array}$ & $\begin{array}{c}19.3 \pm 0.21 \\
14.6 \pm 0.34 \\
13.9 \pm 0.34 * \\
9.0 \\
8.3 \pm 0.17\end{array}$ & $\begin{array}{c}100 \\
50 \\
83 \\
100 \\
83 \\
0\end{array}$ & 46.002 & $<<0.001$ \\
\hline A. bifrons & $\mathrm{a}$ & $\mathrm{CZ}$ & $\begin{array}{l}13 \\
15 \\
17 \\
18 \\
20 \\
21 \\
25 \\
29\end{array}$ & $\begin{array}{c}8 \\
6 \\
6 \\
8 \\
2 \\
6 \\
4 \\
13 \\
-\end{array}$ & $\begin{array}{c}16.0 \pm 0.54 \\
12.1 \pm 0.33 \\
9.2 \pm 0.29 \\
8.3 \pm 0.48 \\
6.8 \pm 0.03 \\
6.8 \pm 0.28 \\
5.2 \pm 0.15 \\
-\end{array}$ & $\begin{array}{c}53 \\
43 \\
53 \\
100 \\
55 \\
24 \\
57 \\
0\end{array}$ & 18.699 & 0.005 \\
\hline A. convexior & $\mathrm{s}$ & $\mathrm{CZ}$ & $\begin{array}{l}15.2 \\
17.7 \\
20.6 \\
25.2 \\
27.6\end{array}$ & $\begin{array}{l}21 \\
17 \\
19 \\
22 \\
28\end{array}$ & $\begin{array}{c}14.6 \pm 0.23 \\
11.7 \pm 0.24 \\
8.1 \pm 0.11 \\
6.2 \pm 0.07 \\
5.2 \pm 0.09\end{array}$ & $\begin{array}{l}72 \\
74 \\
80 \\
80 \\
87\end{array}$ & 3.567 & 0.468 \\
\hline A. convexiuscula & a & $\mathrm{CZ}$ & $\begin{array}{l}18 \\
18.5 \\
19.9 \\
21.9 \\
25.1 \\
27.9\end{array}$ & $\begin{array}{c}20 \\
9 \\
3 \\
5 \\
16 \\
4 \\
5\end{array}$ & $\begin{array}{l}13.3 \pm 0.21 \\
8.7 \pm 0.26 * \\
15.5 \pm 0.12 \\
11.0 \pm 0.04 \\
9.1 \pm 0.07 * \\
8.9 \pm 0.25 *\end{array}$ & $\begin{array}{c}90 \\
100 \\
88 \\
80 \\
55 \\
63\end{array}$ & 11.735 & 0.019 \\
\hline A. equestris & $\mathrm{a}$ & RUS & $\begin{array}{c}12.5 \\
17 \\
20.7 \\
24 \\
28.8\end{array}$ & $\begin{array}{l}16 \\
16 \\
15 \\
13 \\
12\end{array}$ & $\begin{array}{c}22.9 \pm 0.40 \\
14.5 \pm 0.30 \\
9.6 \pm 0.18 \\
7.6 \pm 0.20 \\
6.9 \pm 0.38 *\end{array}$ & $\begin{array}{l}81 \\
86 \\
76 \\
67 \\
59\end{array}$ & 5.170 & 0.270 \\
\hline A. eurynota & $\mathrm{a} / \mathrm{w}$ & $\mathrm{CZ}$ & $\begin{array}{l}12.6 \\
16.9 \\
20.7 \\
24.1 \\
28.7\end{array}$ & $\begin{array}{c}13 \\
9 \\
21 \\
13 \\
7\end{array}$ & $\begin{array}{c}59.9 \pm 2.54 * \\
37.2 \pm 1.27 \\
11.2 \pm 0.74 \\
7.6 \pm 0.27 \\
6.8 \pm 0.99 *\end{array}$ & $\begin{array}{l}79 \\
87 \\
88 \\
54 \\
30\end{array}$ & 26.469 & $<<0.001$ \\
\hline & & RUS & $\begin{array}{c}12.5 \\
16.9 \\
20.7 \\
24 \\
29.3\end{array}$ & $\begin{array}{c}8 \\
13 \\
9 \\
5 \\
2\end{array}$ & $\begin{array}{c}82.5 \pm 3.13 * \\
35.1 \pm 1.25 \\
20.5 \pm 0.64 \\
13.3 \pm 0.83 \\
6.6 \pm 0.30 *\end{array}$ & $\begin{array}{l}62 \\
67 \\
70 \\
80 \\
10\end{array}$ & 26.784 & $<<0.001$ \\
\hline A. municipalis & $\mathrm{a} / \mathrm{w}$ & $\mathrm{CZ}$ & $\begin{array}{l}8.1 \\
12.6 \\
16.9 \\
20.7 \\
28.7\end{array}$ & $\begin{array}{c}6 \\
10 \\
9 \\
6 \\
-\end{array}$ & $\begin{array}{c}101.7 \pm 4.53 \\
54.5 \pm 1.63 \\
33.9 \pm 0.91 \\
22.7 \pm 2.91 \\
-\end{array}$ & $\begin{array}{c}24 \\
37 \\
32 \\
12 \\
0\end{array}$ & 24.408 & $<<0.001$ \\
\hline A. sabulosa & a & $\mathrm{CZ}$ & $\begin{array}{l}13 \\
24.7 \\
18.8 \\
15.6 \\
27.5\end{array}$ & $\begin{array}{l}1 \\
4 \\
8 \\
6 \\
1\end{array}$ & $\begin{array}{c}25.3 \\
13.2 \pm 0.86 \\
11.4 \pm 0.24 \\
7.3 \pm 0.21 \\
7.9 *\end{array}$ & $\begin{array}{l}100 \\
88 \\
100 \\
75 \\
19\end{array}$ & 23.373 & $<<0.001$ \\
\hline P. assimilis & $\mathrm{s}$ & $\mathrm{CZ}$ & $\begin{array}{l}15.2 \\
17.7 \\
20.6 \\
25.2 \\
27.6\end{array}$ & $\begin{array}{l}3 \\
1 \\
2 \\
3 \\
1\end{array}$ & $\begin{array}{c}8.9 \pm 0.56 \\
6.0 \\
3.5 \pm 0.56 * \\
3.3 \pm 0.34 \\
3.0\end{array}$ & $\begin{array}{l}46 \\
13 \\
27 \\
46 \\
29\end{array}$ & 5.3293 & 0.255 \\
\hline P. cupreus & $\mathrm{s}$ & $\mathrm{CZ}$ & $\begin{array}{l}12.7 \\
16.8 \\
20.7 \\
24.3\end{array}$ & $\begin{array}{l}19 \\
23 \\
24 \\
20\end{array}$ & $\begin{array}{c}26.9 \pm 0.74 \\
15.2 \pm 0.31 \\
9.1 \pm 0.14 \\
6.3 \pm 0.13\end{array}$ & $\begin{array}{l}76 \\
76 \\
82 \\
81\end{array}$ & 2.954 & 0.566 \\
\hline P. versicolor & $\mathrm{s}$ & $\mathrm{CZ}$ & $\begin{array}{l}15.2 \\
17.7 \\
20.6 \\
25.2 \\
27.6\end{array}$ & $\begin{array}{l}16 \\
18 \\
19 \\
21 \\
14\end{array}$ & $\begin{array}{l}19.2 \pm 0.37 \\
13.7 \pm 0.27 \\
8.9 \pm 0.16 \\
6.3 \pm 0.11 \\
5.4 \pm 0.15\end{array}$ & $\begin{array}{l}53 \\
63 \\
50 \\
63 \\
53\end{array}$ & 2.497 & 0.645 \\
\hline P. melanarius & $\mathrm{a}$ & $\mathrm{CZ}$ & $\begin{array}{c}12.7 \\
16.8 \\
20.7 \\
24.3 \\
30\end{array}$ & $\begin{array}{l}14 \\
21 \\
33 \\
20 \\
-\end{array}$ & $\begin{array}{c}23.6 \pm 0.60 \\
14.9 \pm 0.23 \\
10.3 \pm 0.10 \\
7.7 \pm 0.08 \\
-\end{array}$ & $\begin{array}{c}22 \\
34 \\
52 \\
34 \\
0\end{array}$ & 58.302 & $<<0.001$ \\
\hline P. oblongopunctatus & $\mathrm{s}$ & $\mathrm{CZ}$ & $\begin{array}{l}15.2 \\
17.7 \\
20.6 \\
25.2 \\
27.6\end{array}$ & $\begin{array}{l}4 \\
4 \\
6 \\
5 \\
4\end{array}$ & $\begin{array}{c}9.9 \pm 0.26 * \\
8.9 \pm 0.41 \\
6.3 \pm 0.20 \\
4.6 \pm 0.25 \\
4.2 \pm 0.26 *\end{array}$ & $\begin{array}{l}63 \\
57 \\
86 \\
71 \\
71\end{array}$ & 1.677 & 0.795 \\
\hline
\end{tabular}

* Not used for estimating thermal constants due to deviance from linearity. 
TABLE 3. Thermal constants for egg development of carabid beetles from 14 populations. CZ - Czech Republic; RUS - Russian Federation.

\begin{tabular}{|c|c|c|c|c|c|c|c|c|}
\hline \multirow{3}{*}{ Species } & \multirow{3}{*}{ Population } & & \multicolumn{6}{|c|}{ Thermal constant $\pm \mathrm{SE}$} \\
\hline & & & \multicolumn{2}{|c|}{ Eq. 2} & \multicolumn{2}{|c|}{ Eq. 3} & \multicolumn{2}{|c|}{ Eq. 4} \\
\hline & & & All data points & Means & All data points & Means & All data points & Means \\
\hline \multirow[t]{2}{*}{ A. aulica } & $\mathrm{CZ}$ & LDT & $2.5 \pm 0.4$ & $2.3 \pm 0.9$ & $2.5 \pm 0.7$ & $2.6 \pm 1.4$ & $2.8 \pm 0.4$ & $2.7 \pm 0.9$ \\
\hline & & SET & $183.1 \pm 6.0$ & $186.5 \pm 14.0$ & $182.4 \pm 7.2$ & $182.2 \pm 14.8$ & $179.1 \pm 5.8$ & $181.4 \pm 12.8$ \\
\hline \multirow[t]{2}{*}{ A. bifrons } & $\mathrm{CZ}$ & LDT & $7.4 \pm 0.3$ & $7.5 \pm 0.2$ & $7.0 \pm 0.5$ & $7.1 \pm 0.5$ & $7.7 \pm 0.3$ & $7.4 \pm 0.3$ \\
\hline & & SET & $89.9 \pm 3.7$ & $89.0 \pm 2.8$ & $93.1 \pm 3.6$ & $92.3 \pm 3.8$ & $88.1 \pm 2.9$ & $89.5 \pm 3.0$ \\
\hline \multirow[t]{2}{*}{ A. convexior } & $\mathrm{CZ}$ & LDT & $8.1 \pm 0.2$ & $8.0 \pm 0.7$ & $8.5 \pm 0.3$ & $8.6 \pm 0.6$ & $8.8 \pm 0.2$ & $8.5 \pm 0.6$ \\
\hline & & SET & $105.7 \pm 2.9$ & $106.0 \pm 8.4$ & $100.6 \pm 2.1$ & $100.6 \pm 4.4$ & $98.7 \pm 2.0$ & $101.3 \pm 5.8$ \\
\hline \multirow[t]{2}{*}{ A. convexiuscula } & $\mathrm{CZ}$ & LDT & $9.3 \pm 0.5$ & $9.3 \pm 0.3$ & $9.4 \pm 0.4$ & $9.5 \pm 0.3$ & $9.9 \pm 0.4$ & $9.4 \pm 0.3$ \\
\hline & & SET & $116.4 \pm 5.7$ & $115.1 \pm 3.6$ & $115.0 \pm 4.5$ & $113.6 \pm 3.5$ & $109.6 \pm 4.7$ & $114.2 \pm 3.5$ \\
\hline \multirow[t]{2}{*}{ A. equestris } & RUS & LDT & $14.4 \pm 0.4$ & $14.4 \pm 0.6$ & $12.8 \pm 1.1$ & $13.4 \pm 1.5$ & $14.1 \pm 0.7$ & $14.2 \pm 0.9$ \\
\hline & & SET & $74.4 \pm 6.9$ & $74.1 \pm 11.6$ & $92.5 \pm 12.8$ & $87.8 \pm 18.0$ & $79.4 \pm 8.2$ & $78.7 \pm 12.9$ \\
\hline \multirow[t]{4}{*}{ A. eurynota } & $\mathrm{CZ}$ & LDT & $15.1 \pm 0.1$ & $15.2 \pm 0.1$ & $14.8 \pm 0.4$ & $14.9 \pm 0.5$ & $15.4 \pm 0.2$ & $15.1 \pm 0.2$ \\
\hline & & SET & $67.2 \pm 4.6$ & $63.6 \pm 3.7$ & $69.4 \pm 4.8$ & $68.6 \pm 5.4$ & $63.6 \pm 3.7$ & $65.5 \pm 4.1$ \\
\hline & RUS & LDT & $12.0 \pm 0.6$ & $12.1 \pm 0.6$ & $12.6 \pm 0.4$ & $12.8 \pm 0.8$ & $12.9 \pm 0.4$ & $12.4 \pm 0.8$ \\
\hline & & SET & $174.9 \pm 19.1$ & $168.4 \pm 18.8$ & $157.6 \pm 10.1$ & $152.0 \pm 18.3$ & $151.1 \pm 10.9$ & $159.8 \pm 19.1$ \\
\hline \multirow[t]{2}{*}{ A. municipalis } & $\mathrm{CZ}$ & LDT & $3.5 \pm 0.3$ & $3.6 \pm 0.5$ & $5.3 \pm 1.0$ & $5.1 \pm 1.2$ & $4.4 \pm 0.4$ & $4.2 \pm 0.7$ \\
\hline & & SET & $475.9 \pm 28.6$ & $456.3 \pm 45.8$ & $372.5 \pm 35.0$ & $372.0 \pm 41.6$ & $418.8 \pm 24.9$ & $413.5 \pm 45.5$ \\
\hline \multirow[t]{2}{*}{ A. sabulosa } & $\mathrm{CZ}$ & LDT & $8.0 \pm 0.6$ & $8.9 \pm 0.9$ & $6.3 \pm 1.0$ & $7.1 \pm 1.4$ & $8.0 \pm 0.7$ & $8.4 \pm 1.1$ \\
\hline & & SET & $116.6 \pm 9.8$ & $100.8 \pm 19.3$ & $136.0 \pm 9.7$ & $128.3 \pm 15.8$ & $119.0 \pm 8.5$ & $112.8 \pm 16.7$ \\
\hline \multirow[t]{2}{*}{ P. assimilis } & $\mathrm{CZ}$ & LDT & $9.4 \pm 1.0$ & $9.4 \pm 0.5$ & $9.0 \pm 1.5$ & $8.6 \pm 0.8$ & $9.6 \pm 0.8$ & $9.0 \pm 0.5$ \\
\hline & & SET & $52.3 \pm 8.0$ & $51.8 \pm 3.6$ & $54.1 \pm 6.1$ & $56.3 \pm 3.4$ & $51.6 \pm 5.4$ & $54.3 \pm 3.1$ \\
\hline \multirow[t]{2}{*}{ P. cupreus } & $\mathrm{CZ}$ & LDT & $8.4 \pm 0.2$ & $8.4 \pm 0.6$ & $9.9 \pm 0.3$ & $9.8 \pm 1.0$ & $9.3 \pm 0.2$ & $9.0 \pm 0.8$ \\
\hline & & SET & $118.7 \pm 4.7$ & $117.6 \pm 14.2$ & $94.4 \pm 2.5$ & $94.7 \pm 9.6$ & $102.2 \pm 2.9$ & $104.8 \pm 12.6$ \\
\hline \multirow[t]{2}{*}{ P. versicolor } & $\mathrm{CZ}$ & LDT & $10.3 \pm 0.2$ & $10.2 \pm 0.4$ & $10.6 \pm 0.3$ & $10.5 \pm 0.4$ & $10.8 \pm 0.2$ & $10.5 \pm 0.3$ \\
\hline & & SET & $96.8 \pm 2.9$ & $96.3 \pm 6.2$ & $91.8 \pm 2.3$ & $92.1 \pm 2.8$ & $90.2 \pm 2.0$ & $92.4 \pm 4.0$ \\
\hline \multirow[t]{2}{*}{ P. melanarius } & $\mathrm{CZ}$ & LDT & $6.6 \pm 0.2$ & $6.5 \pm 0.5$ & $7.6 \pm 0.3$ & $7.5 \pm 0.8$ & $7.4 \pm 0.2$ & $7.0 \pm 0.6$ \\
\hline & & SET & $146.7 \pm 3.8$ & $147.4 \pm 9.8$ & $131.8 \pm 2.8$ & $132.8 \pm 8.4$ & $135.3 \pm 2.8$ & $139.6 \pm 9.3$ \\
\hline P. oblongopunctatus & $\mathrm{CZ}$ & $\begin{array}{l}\text { LDT } \\
\text { SET }\end{array}$ & $\begin{array}{l}10.1 \pm 1.0 \\
68.4 \pm 7.2\end{array}$ & $\begin{array}{l}10.1 \pm 0.5 \\
67.7 \pm 3.6\end{array}$ & $\begin{array}{c}9.6 \pm 1.4 \\
70.7 \pm 7.9\end{array}$ & $\begin{array}{c}9.7 \pm 0.6 \\
70.4 \pm 3.2\end{array}$ & $\begin{array}{l}10.8 \pm 0.9 \\
63.5 \pm 6.3\end{array}$ & $\begin{array}{c}9.9 \pm 0.5 \\
68.9 \pm 3.4\end{array}$ \\
\hline
\end{tabular}

\section{RESULTS}

\section{Thermal constants of egg development and variation in the estimates obtained using different methods}

Mean durations of egg development of 14 populations of 13 species of carabid beetles reared at different temperatures are shown in Table 2. In general the duration of development decreased with increasing temperature but in some species the decrease violated linearity at the temperature extremes. Prior to analysis, such data were excluded (Table 2). Using the remaining data we estimated the thermal constants of development using three models and two data formats, one using the data points for all individuals and the other the means recorded at each temperature (Table 3 ). The thermal constants and the precision of their estimates, represented by SEs, varied among species as well as among the methods used. As expected, the SE values were usually smaller when all the data points were used compared with when means were used (Fig. 2a-d). Additionally, all three formulas produced comparable SEs of estimates, although the SEs obtained using eq. (3) tended to be larger than those obtained using the other two methods.

The values of $L D T$ for the species studied were within a range of $7-11^{\circ} \mathrm{C}$ for most species (Table 3), with few exceptions: $A$. municipalis and $A$. aulica with a $L D T$ of approximately $3-4^{\circ} \mathrm{C}$, and $A$. equestris and $A$. eurynota (Czech population) with a $L D T$ of approximately $14-15^{\circ} \mathrm{C}$. The values of $S E T$ varied greatly among the species (Table $3)$. Overall, the lowest estimated values of SET were recorded for $P$. assimilis (approximately 50-55 dd, depending on the method). Most of the species had SET values for egg development between 90 and $130 \mathrm{dd}$. Notably longer developmental times and higher SETS were recorded for $A$. aulica, A. eurynota (Russian population), A. municipalis and $P$. melanarius, of which $A$. municipalis had by far the highest $S E T$ value of the species studied.

In some species, the variation in thermal constants recorded using the different methods was very small (Table 3 ), only within a range of $0.5-1.0^{\circ} \mathrm{C}$ in the case of $L D T$ and below $10 \mathrm{dd}$ in the case of SET. However, for a few species, the variation exceeded $1.5^{\circ} \mathrm{C}$ in the case of $L D T$ (A. equestris, A. municipalis, A. sabulosa and P. cupreus) and 50-100 dd in the case of SET (same four species as for LDT plus $A$. eurynota (Russian population) and $P$. melanarius). Despite this inconsistent degree of variation, the thermal constants were strongly negatively inter-correlated across all methods of estimation in all the species studied $(\mathrm{p}<<0.001$ and $\mathrm{r}>-0.98$ in all cases; Fig. 2e-f). Thus, 

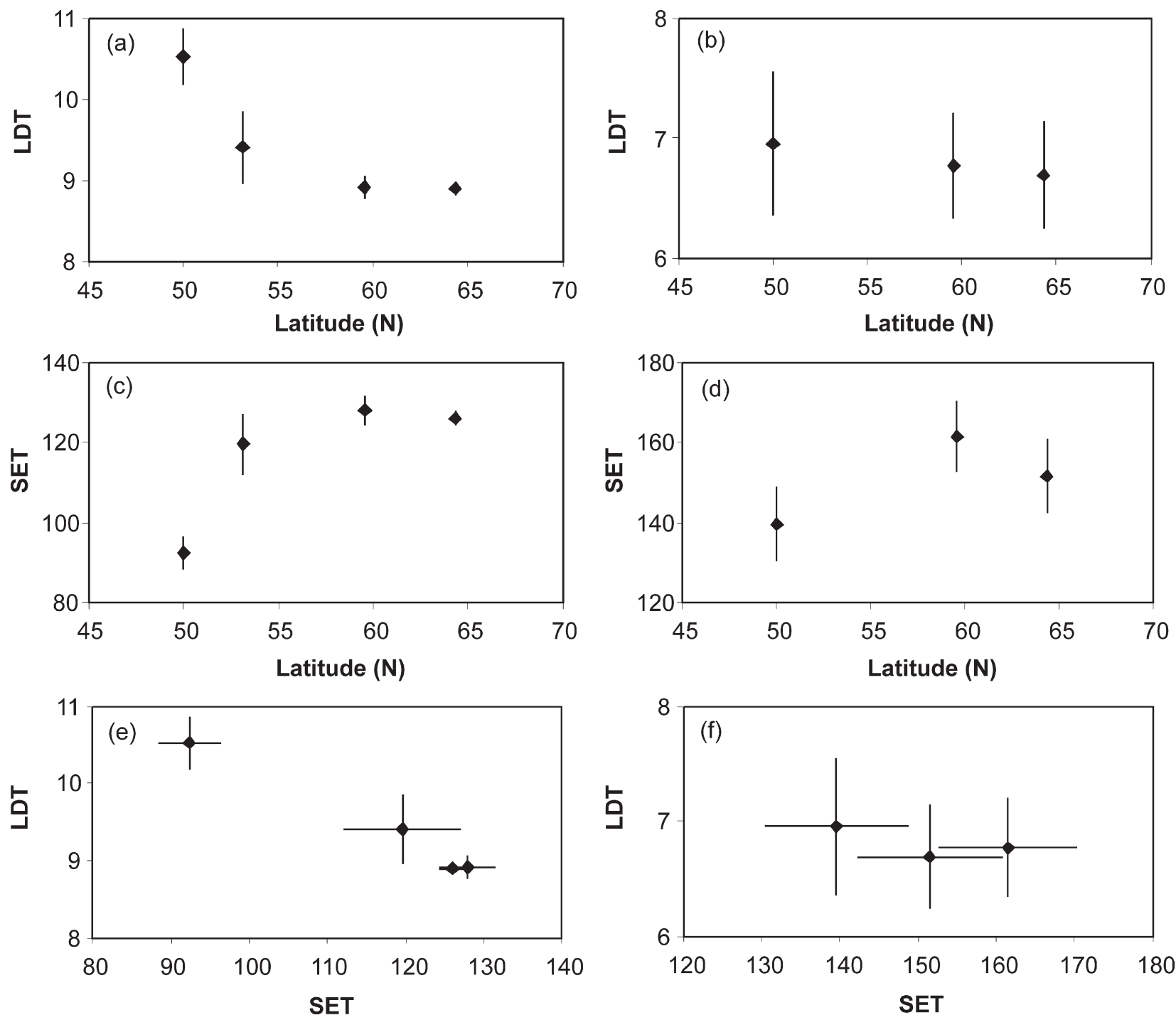

Fig. 3. Geographical variation in the thermal constants of egg development, estimated using eq. 4 and means. Error bars represent SE: (a-b) variation in $L D T$ with geographical latitude; (c-d) variation in SET with geographical latitude; (e-f) correlation between $L D T$ and SET. (a), (c) and (e) - Poecilus versicolor; (b), (d) and (f) - Pterostichus melanarius.

when a method of estimation provided a higher than average $L D T$ across methods, the corresponding value of SET decreased.

\section{Geographical variation in thermal constants of egg development}

The geographical variation in the estimated thermal constants was studied for seven species using mean durations of development. In most of the seven species, we detected a pattern of increasing SET and decreasing $L D T$ with latitude (exemplified by $P$. versicolor and $P$. melanarius in Fig. 3); however, the overall differences in thermal constants across sites were significant at $\mathrm{p}<0.05$ for only three species ( $P$. versicolor, $P$. assimilis and $P$. oblongopunctatus) for both thermal constants and in A. eurynota for SET (Table 4). Significant differences in LDT between populations at $\mathrm{p}<0.10$ were further recorded for $A$. eurynota and $A$. equestris. In $A$. eurynota we could repeat the analysis using all data points and found that both $L D T$ and SET varied between populations at $\mathrm{p}<0.05$ (Table 4 ). In this species the recorded difference between populations were especially high for SET, which was more than two times higher in the Russian than the Czech population (Fig. 4; Table 3).

\section{The effect of temperature on egg mortality}

The overall mortality varied among species and was generally low in spring-breeding species (Table 2), except for $P$. assimilis, in which the average mortality exceeded $50 \%$ at all temperatures. In all spring-breeding species, there was no significant effect of temperature on egg mortality (Table 2). In autumn- and winter-breeding species, the mortality recorded at different temperatures varied and increased significantly at the highest temperatures (Table 2); in some species, egg development could not be completed at temperatures above $25^{\circ} \mathrm{C}(P$. melanarius, $A$. municipalis, $A$. aulica, and $A$. bifrons). The only exception among the autumn-breeding species was $A$. equestris, in which egg mortality was unaffected by temperature (Table 2).

\section{DISCUSSION}

In this study, we investigated the variation in thermal constants of egg development in several carabid beetles. In 


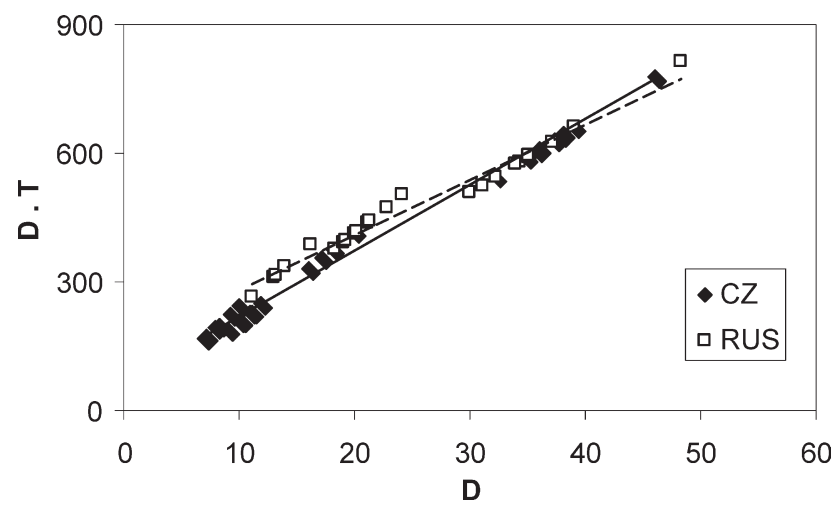

Fig. 4. Differences in thermal constants of egg development recorded for Russian and Czech populations of A. eurynota. Czech population (solid line): $D \cdot T=15.4 D+63.58$; Russian population (dashed line): $D \cdot T=12.9 D+151.12$.

most species, the $L D T$ ranged between $7-11^{\circ} \mathrm{C}$, and exceptions may be explained by the biology of these species in most cases. A. municipalis reproduces in late autumn and winter (Bílý, 1975) and the very low $L D T$ of approximately $4^{\circ} \mathrm{C}$ may be regarded as adaptive as it enables the egg to develop in winter when temperatures are generally low. Similarly, low values of $L D T$ were estimated for A. aulica, but this is an early autumn reproducing species (Hůrka \& Ducháč, 1980), so we cannot provide an ecological explanation for this result, especially when other species that reproduce in the same season have $L D T \mathrm{~s}$ within the typical range. In contrast to $A$. municipalis, A. eurynota, which is another species that reproduces in late autumn and over winter (Bílý, 1972; P. Saska, pers. obs.), the $L D T$ was unexpectedly high especially in the Czech population and similar to that of $A$. equestris, which is a warm-adapted xerophilous species (Hůrka, 1996). What kind of ecological mechanism may be determining such a high $L D T$ in species that reproduces in the coldest period of the year is unknown. In general, the values of $S E T$ varied to a greater extent among species and reflected the duration of development at a particular temperature.

It has been widely recognised that the thermal constants are inter-correlated as the estimates originate from the same equation (Campbell et al., 1974), but a convincing demonstration of this inter-correlation cannot be found in the literature. The results of several authors who compared two methods for estimating thermal constants indicate that this correlation may occur (e.g., Koda \& Nakamura, 2012; Kuang et al., 2012); however, there has been no attempt to provide proof of this correlation. As we estimated the thermal constants for each species using six different methods we were able to test whether such an inter-correlation exists. Although the thermal constants were estimated from the same data and all three equations used are indeed different expressions of the law of total effective temperatures (Damos \& Savopoulou-Soultani, 2012), within-species differences in the estimated values of the thermal constants occurred to some extent in all species. Using these data, we were able to demonstrate the existence of an inter-correlation between $L D T$ and SET for all the species studied, re-

TABLE 4. Geographical variation in the thermal constants of egg development recorded for seven species of carabid beetles. The letters beside the thermal constants \pm SE indicate differences among populations within the same species based on ANCOVA. Mean duration of development at each temperature was used in the analysis.

\begin{tabular}{|c|c|c|c|}
\hline Species & Population & $\mathrm{LDT} \pm \mathrm{SE}$ & $\mathrm{SET} \pm \mathrm{SE}$ \\
\hline A. convexior & Praha & $8.5 \pm 0.39 \mathrm{a}$ & $101.3 \pm 3.80 \mathrm{a}$ \\
\hline \multirow[t]{2}{*}{$(\text { A. communis })^{1}$} & St. Petersburg & $7.8 \pm 0.44 \mathrm{a}$ & $109.6 \pm 4.88 \mathrm{a}$ \\
\hline & Archangelsk & $7.6 \pm 0.44 \mathrm{a}$ & $110.7 \pm 4.94 \mathrm{a}$ \\
\hline \multirow[t]{2}{*}{ A. equestris } & Praha & $14.2 \pm 0.64 \mathrm{a}$ & $78.7 \pm 9.32 \mathrm{a}$ \\
\hline & Moscow & $9.4 \pm 0.64 \mathrm{a}$ & $109.5 \pm 17.80 \mathrm{a}$ \\
\hline \multirow[t]{2}{*}{ A. eurynota } & Praha & $15.1 \pm 0.40 \mathrm{a}$ & $65.5 \pm 9.06 \mathrm{a}$ \\
\hline & Moscow & $12.4 \pm 0.70 \mathrm{a}$ & $159.8 \pm 16.87 \mathrm{~b}$ \\
\hline \multirow[t]{4}{*}{ P. assimilis } & Praha & $9.0 \pm 0.54 \mathrm{a}$ & $54.3 \pm 3.18 \mathrm{a}$ \\
\hline & Moscow & $8.0 \pm 0.72 \mathrm{ab}$ & $75.7 \pm 5.17 b$ \\
\hline & St. Petersburg & $8.0 \pm 0.72 \mathrm{ab}$ & $75.6 \pm 5.10 b$ \\
\hline & Archangelsk & $6.6 \pm 0.87 \mathrm{~b}$ & $84.1 \pm 6.76 b$ \\
\hline \multirow[t]{4}{*}{ P. versicolor } & Praha & $10.5 \pm 0.34 \mathrm{a}$ & $92.4 \pm 4.07 \mathrm{a}$ \\
\hline & Bryansk & $9.4 \pm 0.46 b$ & $119.6 \pm 6.59 \mathrm{~b}$ \\
\hline & St. Petersburg & $8.9 \pm 0.38 b$ & $128.0 \pm 5.71 b$ \\
\hline & Archangelsk & $8.9 \pm 0.37 b$ & $126.0 \pm 5.28 \mathrm{~b}$ \\
\hline \multirow[t]{3}{*}{ P. melanarius } & Praha & $7.0 \pm 0.53 \mathrm{a}$ & $139.6 \pm 8.12 \mathrm{a}$ \\
\hline & St. Petersburg & $6.8 \pm 0.68 \mathrm{a}$ & $161.5 \pm 12.00 \mathrm{a}$ \\
\hline & Archangelsk & $6.7 \pm 0.76 \mathrm{a}$ & $151.5 \pm 13.95 \mathrm{a}$ \\
\hline \multirow[t]{6}{*}{ P. oblongopunctatus } & Praha & $9.9 \pm 0.97 \mathrm{a}$ & $68.9 \pm 6.65 \mathrm{a}$ \\
\hline & Burscheid & $8.2 \pm 1.10 \mathrm{ab}$ & $90.9 \pm 8.30 b$ \\
\hline & Baarn & $6.8 \pm 0.98 b$ & $94.1 \pm 7.13 b$ \\
\hline & Moscow & $7.7 \pm 1.07 \mathrm{ab}$ & $98.7 \pm 8.20 \mathrm{~b}$ \\
\hline & St. Petersburg & $7.4 \pm 1.01 \mathrm{ab}$ & $103.9 \pm 8.13 b$ \\
\hline & Archangelsk & $7.6 \pm 1.12 \mathrm{ab}$ & $96.4 \pm 9.08 \mathrm{~b}$ \\
\hline \multirow[t]{2}{*}{ A. eurynota ${ }^{2}$} & Praha & $15.4 \pm 0.21 \mathrm{a}$ & $63.6 \pm 4.23 \mathrm{a}$ \\
\hline & Moscow & $12.9 \pm 0.39 \mathrm{~b}$ & $151.1 \pm 10.10 \mathrm{~b}$ \\
\hline
\end{tabular}

${ }^{1}$ Closely related species from one species group. ${ }^{2}$ All data points were used in this comparison. 
gardless of the magnitude of variation among the estimated thermal constants. In other words, if the value of one of the thermal constants increased, the value of the other constant for the same data decreased proportionally. As a result of such inter-correlation, Campbell et al. (1974) claimed that the predicted rates of development would be hardly affected over the range of ecologically relevant temperatures, except at temperatures close to the estimated value of $L D T$. We tested this assumption, and found that, in most cases, the predicted duration of development at $20^{\circ} \mathrm{C}$ obtained using the different methods differed by no more than $5 \%$ of the mean predicted duration (data not shown). The situations in which the difference was greater were most likely due to a poorer fit of the model to the data. The proof of the existence of this inter-correlation has, in our opinion, one important consequence - comparison of trends in one thermal constant can only be made when the other thermal constant is also considered; variations in the values of a thermal constant estimated may have been introduced by the shift in the other thermal constant in the opposite direction.

We compared six ways of estimating thermal constants using three models and data in two formats, which all have advantages and disadvantages. The advantage of the classical linear method (eq. (3) in this paper) is that it is very intuitive and demonstrative. However, this method often provided the highest SE's of the three models regardless of data format. Before using this method and all the data points several statistical assumptions (homogeneity of variances among temperatures, equal sample size, etc.) must be fulfilled. Another caveat of this method is the LDT and SET must be calculated from the estimated regression coefficients (Campbell et al., 1974). In contrast, eq. (2) and eq. (4) both enable the SE of the estimates of the thermal constants to be obtained directly from the output of the regression analysis. Eq. (2), which is also rather intuitive when displayed, is a non-linear equation; therefore, the thermal constants cannot be as easily calculated using this equation as the other two models using spreadsheet software. Advanced statistical software for non-linear regression must be used, which may be limiting for some researchers and practitioners. In the case of eq. (2), statistical assumptions also need to be fulfilled to allow all data points to be used in the analysis. For all of these reasons, we prefer using eq. (4) for estimating thermal constants. This equation is easy to compute in spreadsheet software without the need for special statistical software. The major advantages of this method are that all data points can be used as there are no underlying statistical assumptions, variance of the estimates of thermal constants can be estimated directly from the analysis and the thermal requirements of different species or populations can be easily compared using analysis of covariance (with species / population as a factor) as the thermal constants are parameters of the equation. We have successfully used this approach in this study using mean durations of development at a particular temperature. Although we lost some statistical power, as demonstrated by the case of $A$. eurynota, for which we could perform the analysis of geographical differences on both data formats, it provides a means of re-analysing and comparing published data with a high degree of precision.

One of the most important aims of our study was to investigate the geographical variation in thermal constants of egg development. We found sufficient data in the literature for comparing with our data on seven species (Paarmann, 1966; Heessen et al., 1982; Saska \& Honěk, 2003; Lopatina et al., 2012b). The pattern of variation in the estimated values of the thermal constants conforms to that described in the literature, LDT decreased and SET increased with geographical latitude (Trudgill \& Perry, 1994; Honěk, 1996a), despite the arguments of Lopatina et al. (2012a) that the egg is not a suitable stage for performing geographical comparisons of thermal requirements as it develops in soil, which buffers it from variations in ambient temperature. However, when analysing latitudinal trends, we could not statistically confirm the differences for all of the species studied based on an analysis of covariance. One argument may be that the differences might have originated from the same sort of inter-correlation that complicated the comparison of methods. We assume that this is not the case from two reasons. First, the thermal constants were estimated using different data sets. Second, we previously recorded auto-correlations in the thermal constants of species for which there were no significant latitudinal trends. Thus, the recorded differences between populations should be regarded as real geographical variation, i.e., the result of adaptations to different geographical conditions.

For several species of carabids, temperature affected the survival of their eggs. These were the autumn-breeding species that cannot tolerate high temperatures during their development, so this phenomenon is apparently an adaptation to cold autumn conditions. It might be interesting to investigate whether this "heat-intolerance" also varies geographically; however, no data are currently available to determine whether this is the case for carabid beetles.

In conclusion, we compared six different ways of estimating the thermal constants of egg development in carabid beetles. We critically evaluated the advantages and disadvantages of the individual methods. We recommend the model developed by Ikemoto \& Takai (2000) for its precision, lack of statistical assumptions and simplicity of calculation, both for estimating the constants and their SE's. This method also enables a rigorous comparison of the thermal constants among species and populations using complete or averaged data from the literature. We successfully used this model to test for geographical variation in thermal constants, which in our study, conforms to the general theory, but not for all species.

ACKNOWLEDGEMENTS. This work was supported by grants LH12210 from the Ministry of Education and Youth and Sports of the Czech Republic to P.S. and No. 12-04-01178a from the Russian Foundation for Basic Research to A.M. We thank K. Šímová for her help with rearing $A$. bifrons and A. Honěk for critically reading an early draft of this manuscript. 


\section{REFERENCES}

Bílý S. 1972: Larva of Amara (Amara) eurynota (Panzer) (Coleoptera, Carabidae) and notes on bionomy of this species. Acta Entomol. Bohemoslov. 69: 324-329.

Bílý S. 1975: Larvae of the genus Amara (subgenus Celia Zimm.) from central Europe (Coleoptera, Carabidae). — Studie ČSAV 13: $1-74$.

Bonato O., Iкemoto T., Shi P., Ge F., Sun Y. \& Cao H. 2011: Common-intersection hypothesis of development rate lines of ectotherms within a taxon revisited. $-J$. Therm. Biol. 36 : 422-429.

Campbell A., Frazer B.D., Gilbert N., Gutierrez A.P. \& MACKAUER M. 1974: Temperature requirements of some aphids and their parasites. - J. Appl. Ecol. 11: 431-438.

Crawley M.J. 2007: The R Book. John Wiley \& Sons, Chichester, 942 pp.

Damos P. \& Savopoulou-Soultani M. 2012: Temperature-driven models for insect development and vital thermal requirements. - Psyche Article ID 123405: 13 pp.

Heessen H.J.L., Wildschut M.A. \& Brunsting A.M.H. 1982: Duration of the developmental stages and timing of the end of the reproductive season of Pterostichus oblongopunctatus (Fabricius) (Col., Carabidae) and Philonthus decorus (Gravenhorst) (Col., Staphylinidae). — Neth. J. Zool. 32: 49-62.

HoNĚK A. 1996a: Geographical variation in thermal requirements for insect development. - Eur. J. Entomol. 93: 303-312.

HonĚK A. 1996b: The relationship between thermal constants for insect development: a verification. - Acta Soc. Zool. Bohem. 60: $115-152$.

Honěk A., Martinková Z., Saska P. \& Pekár S. 2007: Size and taxonomic constraints determine the seed preferences of Carabidae (Coleoptera). - Basic Appl. Ecol. 8: 343-353.

HưRKa K. 1996: Carabidae České a Slovenské republiky. [Carabidae of the Czech and Slovak Republics.] Kabourek, Zlín, 565 pp. [in Czech and English].

HƯRKA K. \& DuChÁČ V. 1980: Larval descriptions and the breeding type of the central European species of Amara (Curtonotus) (Coleoptera, Carabidae). - Acta Entomol. Bohemoslov. 77: $258-270$.

HŮRKA K. \& JAROŠÍK V. 2001: Development, breeding type and diet of members of the Amara communis species aggregate (Coleoptera: Carabidae). - Acta Soc. Zool. Bohem. 65: 17-23.

Iкемото T. 2003: Possible existence of a common temperature and a common duration of development among members of a taxonomic group of arthropods that underwent speciational adaptation to temperature. - Appl. Entomol. Zool. 38: 487-492.

Iкемото T. \& TAKaI K. 2000: A new linearized formula for the law of total effective temperature and the evaluation of linefitting methods with both variables subject to error. - Environ. Entomol. 29: 671-682.

Jarošík V., Kratochvíl L., HoněK A. \& Dixon A.F.G. 2004: A general rule for the dependence of developmental rate on temperature in ectothermic animals. - Proc. R. Soc. Lond. (B) 271: S219-S221.
Jarošík V., HonĚK A., Magarey R.D. \& Skuhrovec J. 2011: Developmental database for phenology models: Related insect and mite species have similar thermal requirements. - $J$. Econ. Entomol. 104: 1870-1876.

Koda K. \& NaKamura H. 2012: Effects of the temperature on the development and survival of an endangered butterfly, Lycaeides argyrognomon (Lepidoptera: Lycaenidae) with estimation of otpimal and threshold temperatures using linear and nonlinear models. - Entomol. Sci. 15: 162-170.

Kontodimas D.C., Eliopoulos P.A., Stathas G.J. \& Economou L.P. 2004: Comparative temperature-dependent development of Nephus includens (Kirsch) and Nephus bisignatus (Boehman) (Coleoptera: Coccinellidae) preying on Planococcus cotri (Risso) (Homoptera: Pseudococcidae): Evaluation of a linear and various nonlinear models using specific criteria. Environ. Entomol. 33: 1-11.

Kuang X.-J., Parajulee M.N., Shi P.-J., Ge F. \& Xue F.-S. 2012: Testing the rate isomorphy hypothesis using five statistical methods. - Insect Sci. 19: 121-128.

Lopatina E.B., Kipyatkov V.E., Balashov S.V., Dubovikoff D.A. \& Sokolova I.V. 2012a: Adaptive latitudinal variation of the duration and thermal requirements for development in the ground beetle Amara communis (Panz.) (Coleoptera, Carabidae). - Entomol. Rev. 92: 135-145.

Lopatina E.B., Kipyatkov V.E., Balashov S.V., Dubovikoff D.A. \& SoKolova I.V. 2012b: Interspecific and intraspecific variation of the duration and thermal requirements for egg development in carabid beetles (Coleoptera, Carabidae) in the NorthWest of Russia. - Entomol. Rev. 92: 32-45.

PaARmann W. 1966: Vergleichende Untersuchungen über die Bindung zweier Carabidenarten (P. angustatus Dft. und P. oblongopunctatus $\mathrm{F}$.) an ihre verschidenen Lebensräume. $-Z$. Wiss. Zool. 174: 83-166.

R Development Core Team 2013: R: A Language and Environment for Statistical Computing. http://www.R-project.org R Foundation for Statistical Computing, Vienna, Austria. Available at http://www.R-project.org.

SASKA P. \& HoNĚK A. 2003: Temperature and development of central European species of Amara (Coleoptera: Carabidae). - Eur. J. Entomol. 100: 509-515.

Sokal R.R. \& RohlF F.J. 1981: Biometry. 2nd ed. W.H. Freeman, San Francisco, 859 pp.

Stacey D.A. \& Fellowes M.D.E. 2002: Temperature and the developmental rates of thrips: Evidence for a constraint on local adaptation? - Eur. J. Entomol. 99: 399-404.

Trudgill D.L. \& Perry J.N. 1994: Thermal time and ecological strategies - a unifying hypothesis. - Ann. Appl. Biol. 125: 521-532.

Trudgill D.L., HoněK A., Li D. \& van Straalen N.M. 2005: Thermal time - concepts and utility. - Ann. App. Biol. 146: $1-14$.

Received January 13, 2014; revised and accepted March 17, 2014 Prepublished online September 10, 2014 